\title{
Advances for the on-site determination of the stresses state in timber structures in service
}

\author{
M. Crespo de Antonio, D. Luengas-Carreño \& S. Sánchez-Beitia \\ Higher Technical School of Architecture UPV/EHU, Spain
}

\begin{abstract}
The assessment of nondestructive (NDT) or semi-destructive techniques (SDT) for the in situ structural characterization in existing constructions is one of the most important challenges for the scientific community. The hole-drilling method is considered as a SDT because the damage caused to the analyzed element affects neither its integrity nor its load-bearing capacity. The experimental process is to measure the relaxed strains caused by the removal of a small round of material. These relaxed strains are recorded by previously well adhered strain gages according to the corresponding ASTM standard. It is possible to deduce the stress status before the material removal using the correct mathematical scheme.

This paper shows the advances of the setting of the hole-drilling method for the deduction of the stress-state on supporting wood members in existing structures (buildings and civil constructions). The relationship between the relaxed strains after removing the material and the stress that causes them has been identified in the laboratory by means of the deduction of its corresponding compliance matrix. The laboratory-tested samples of Pinus radiata D. Don had a structural size, being loaded under a known uniaxial compression imitating piers. The main goal is to complete compliance matrix for this material and for compression situations. The matrix will be useful in deducing the real stresses in regions of timber structural members made of this kind of wood.

Keywords: on site assessment, hole-drilling technique, timber structures, ancient constructions, compliance tensor, compression loading.
\end{abstract}

\section{Introduction}

Wood is one of the oldest structural materials and it has been widely used where there was a forest. Due to the increasing desire to preserve the historical value of 
ancient buildings and the fact it is the only truly renewable material, wood has experienced a renaissance in construction after being forgotten for a while when other attractive modern materials appeared. For many years wood was the only material able to solve horizontal structures, so it is quite usual to find up timber structures in restoration works. There are many methods for the assessment of physical and mechanical properties of timber structures in service which are constantly being improved and developed. Nevertheless, more research is required to estimate individual member strengths as well as obtain accurate quantification of deterioration [1].

Hole-drilling is not included between evaluating and assessing methods in existing timber structures but it could provide the necessary information to predict in situ member strength [1]. Although hole-drilling is not a new method, indeed it is based on the ASTM E837 standard [2] it does not consider its application on wood, a natural orthotropic material. This technique was limited to being used in isotropic materials in other fields of the knowledge far from heritage.

Wood is an orthotropic material because its three main directions (axial, radial and tangential) are orthogonal one to another. This means that wood features are different in each main direction, being the strongest one along the axial direction.

The aim of this research is to include the hole-drilling between in situ assessment techniques of structural timber. There are some techniques based on stress waves, sounding, ground penetrating radar, radiography, resistance drilling, core-drilling, hardness test and some others [3-5], but none useful to estimate the stress status of a wooden element in service.

\section{Hole-drilling technique}

Since its inception by Mathar in the 1930s [6], the hole-drilling method has grown to be one of the most popular procedures to obtain the stresses [7], more specifically residual stresses, in a wide variety of materials [8]. For instance, Sanchez-Beitia and Schueremans [9], Sanchez-Beitia et al. [10] and SanchezBeitia and Roca [11] have researched the method in masonry structures, considered an isotropic material. The procedure involves registering the strain relaxation that is originated when a round of material is removed by drilling. The strain-values are recorded by three strain gages previously glued over the material surface around the point where the drill is going to be made. The three gages enable to know the stress state before drilling. This procedure is considered to be a minor destructive test because the hole made by the drill is so small that it does not damage the wholeness of the analyzed wooden element. Three strain gages are enough to complete a rosette and determine the state of the stresses in two-dimensional situations. The involved dimensions (strain gages rosette location, hole-diameter and depth of drilling) are well established on the ASTM E837 Standard. The rosettes must be handmade for each analyzed point because no commercial device is available for wood. According to the standard recommendations but also to the available boring tool $(18 \mathrm{~mm}$ in drill bit- 
diameter) and commercial strain gages size (12 $\mathrm{mm}$ in length), new dimensions for the experimental situation are $18 \mathrm{~mm}$ in hole-diameter, $16 \mathrm{~mm}$ in depth of drill, $40 \mathrm{~mm}$ in rosette-diameter. Despite this increase, proportions between holediameter, strain gages size, and the circumference diameter of the strain gages disposal have been maintained in order to ensure the stresses relaxation after the elimination of material after drilling.

The experimental procedure explained here has been developed for Pinus radiata $\mathrm{D}$. Don because it is a widely used material as a building material for timber structures in many zones of Europe. Wood is an orthotropic material with two main orthotropic directions of elasticity named, in this case, $x$ and $y$, which their related elasticity moduli are named Ex (transversal-to-grain direction) and $E y$ (fibre direction). It is generally assumed that radial and tangential directions can be considered similar in terms of physic and mechanical properties but very different in comparison with the axial one. In this case, transversal direction is assumed to be both radial and tangential. All the stress-states are deduced in a plane state of stresses where the principal directions coincide with the fibre and tangential directions shown in figs 1 and 2. In a plane state of stresses the correlation between the relaxed trains after the elimination of material and the stress supported by the material is shown in eqn. $(1)[12,13]$.

$$
\left(\begin{array}{ccc}
c_{11} & 0 & c_{13} \\
c_{21} & c_{22} & c_{23} \\
c_{31} & 0 & c_{33}
\end{array}\right)\left(\begin{array}{l}
\sigma_{y} \\
\sigma_{x y} \\
\sigma_{x}
\end{array}\right)=\sqrt{E_{x} E_{y}}\left(\begin{array}{l}
\varepsilon_{1} \\
\varepsilon_{2} \\
\varepsilon_{3}
\end{array}\right)
$$

In this equation $c i j$ are the dimensionless constants of compliance. When $x$ and $y$ directions of the rosette coincide with the principal elastic directions of the orthotropic material, the compliances $c_{12}$ and $c_{32}$ both equal zero [12]. $\sigma y, \sigma x y$ and $\sigma x$ are the stresses in the $x-y$ plane. $\varepsilon_{1}, \varepsilon_{2}$, and $\varepsilon_{3}$ are the relaxed strains recorded by three strain gages (figs 1 and 2). Ex and Ey are the principal moduli of elasticity. The reference system shown in fig. 1 has been applied in all the tests. Two gages are in mutually perpendicular directions, with a third along one of the bisectors; $y$ axis, where strain gage 1 is placed, coincides with the fibre direction, whereas the $x$ axis, where strain gage 3 is placed, always coincides with the transversal direction (fig. 2).

From eqn. (1) the following expressions can be obtained.

$$
\begin{aligned}
& c_{11} \sigma_{y}+c_{13} \sigma_{x}=\sqrt{E_{x} E_{y}} \varepsilon_{1} \\
& c_{21} \sigma_{y}+c_{22} \sigma_{x y}+c_{23} \sigma_{x}=\sqrt{E_{x} E_{y}} \varepsilon_{2} \\
& c_{31} \sigma_{y}+c_{33} \sigma_{x}=\sqrt{E_{x} E_{y}} \varepsilon_{3}
\end{aligned}
$$




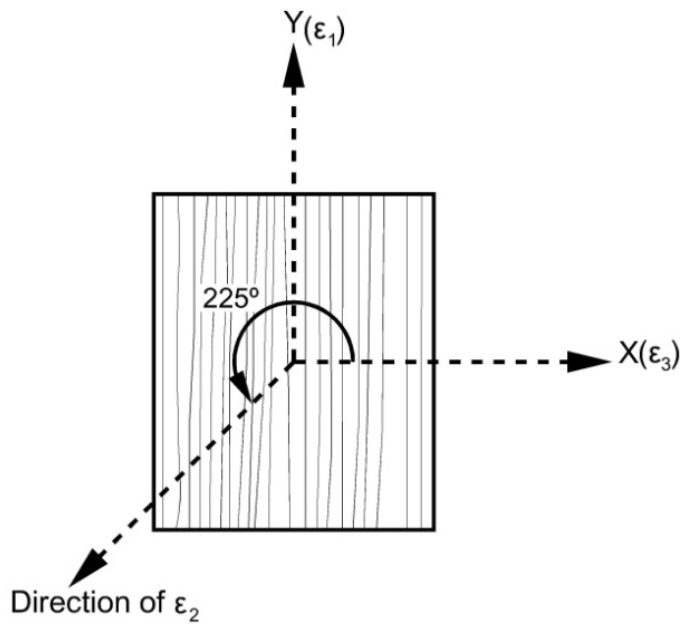

Figure 1: Plane reference system where fibre direction coincides with the $y$ axis. The lines drawn model the fibre direction.
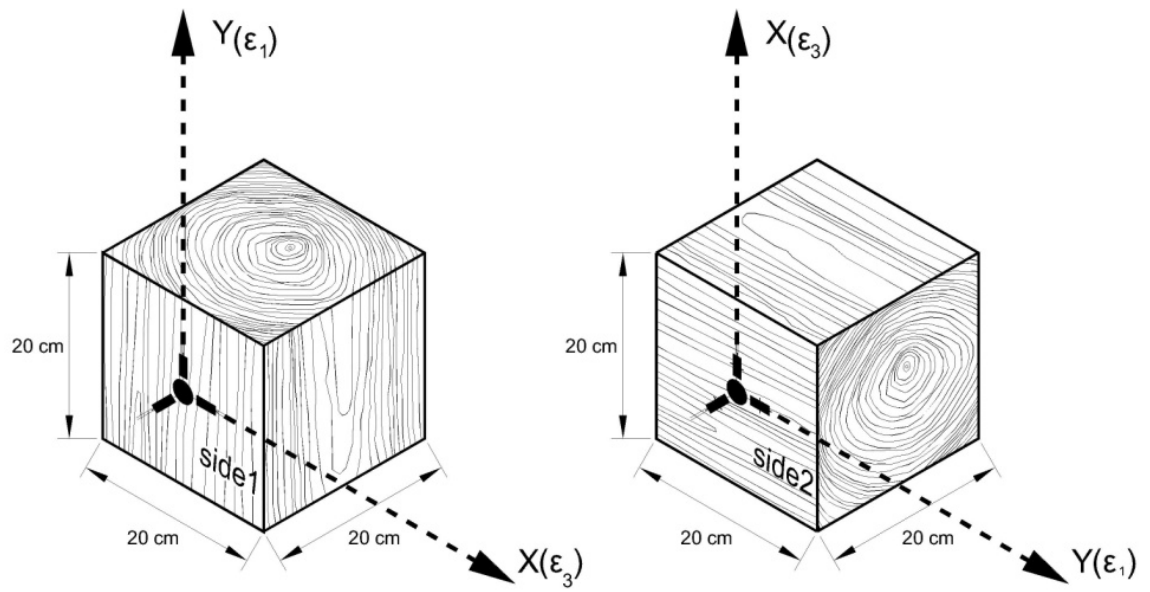

Figure 2: Schematic sight of the tested blocks, hole-position (dark circle) and strain gages location (dark rectangles). Blocks have been tested under uniaxial compression in axial (left) and tangential direction (right).

\section{Analytical and experimental planning}

Ten blocks $(20 \mathrm{~cm} \times 20 \mathrm{~cm}$ x $20 \mathrm{~cm}$ ) have been loaded at the laboratory. The material has been taken from a forest in the north of Spain and has been cut and tested without any previous treatment. The environmental conditions of the laboratory are $20^{\circ} \mathrm{C}$ and $50 \%$ of relative humidity. The material conditions 
reproduce the real being of timber structures in existing buildings where this research is going to be continued in the following months. However, the values of the elasticity moduli in the bibliography for blocks with these dimensions and this kind of wood are not available [14].

When the blocks are loaded under a known axial compression $\left(\sigma y^{c}\right)$ in $y$ direction, the constants of compliance $c_{11}, c_{21}$ and $c_{31}$ can be obtained from a hole-drilling test by using the following expressions obtained from eqns (2), (3) and (4), being $\sigma x=\sigma x y=0$ :

$$
\begin{aligned}
& c_{11} \sigma_{y}{ }^{c}=\sqrt{E_{x} E_{y}} \varepsilon_{1} \\
& c_{21} \sigma_{y}{ }^{c}=\sqrt{E_{x} E_{y}} \varepsilon_{2} \\
& c_{31} \sigma_{y}{ }^{c}=\sqrt{E_{x} E_{y}} \varepsilon_{3}
\end{aligned}
$$

The same process has been repeated loading the blocks under a known transversal/tangential compression $\left(\sigma x^{c}\right)$ in the $x$ direction. The constants of compliance $c_{13}, c_{23}$ and $c_{33}$ can be obtained from a hole-drilling test using the following expressions obtained from eqns (2), (3) and (4), in this case $\sigma y=\sigma x y=$ 0 :

$$
\begin{aligned}
& c_{13} \sigma_{x}{ }^{c}=\sqrt{E_{x} E_{y}} \varepsilon_{1} \\
& c_{23} \sigma_{x}{ }^{c}=\sqrt{E_{x} E_{y}} \varepsilon_{2} \\
& c_{33} \sigma_{x}{ }^{c}=\sqrt{E_{x} E_{y}} \varepsilon_{3}
\end{aligned}
$$

A complementary test has to be designed to obtain the constant of compliance $c_{22}$. Once the blocks have been tested under axial and transversal/tangential loads, ten new samples are obtained from the originals and cut to achieve the ten new blocks with the fibre directions tilted (as shown in fig. 3). Their final dimensions are $12 \mathrm{~cm} \times 12 \mathrm{~cm}$ in section and $14 \mathrm{~cm}$ in height. These blocks have been tested under a known compression load $\left(\sigma^{c}\right)$.

The following expression shows the correlation between the $\sigma^{\mathrm{c}}$ and the stress state in the $x-y$ system reference:

$$
\left(\begin{array}{c}
\sigma_{x} \\
\sigma_{x y} \\
\sigma_{y}
\end{array}\right)=\left(\begin{array}{c}
\sigma^{c} \operatorname{sen}^{2} \theta \\
-\sigma^{c} \operatorname{sen} \theta \cos \theta \\
\sigma^{c} \cos ^{2} \theta
\end{array}\right)
$$

From eqns (3) and (11) can be obtained the following expression which allows the deduction of $c_{22}$ :

$$
c_{21} \sigma^{c} \cos ^{2} \theta+c_{22}\left(-\sigma^{c} \operatorname{sen} \theta \cos \theta\right)+c_{23} \sigma^{c} \operatorname{sen}^{2} \theta=\sqrt{E_{x} E_{y}} \varepsilon_{2}
$$


By loading the new blocks under a known stresses $\left(\sigma^{c}\right)$, a hole-drilling procedure solves the problem as $c_{21}$ and $c_{23}$ have been previously determined in eqns (6) and (9).

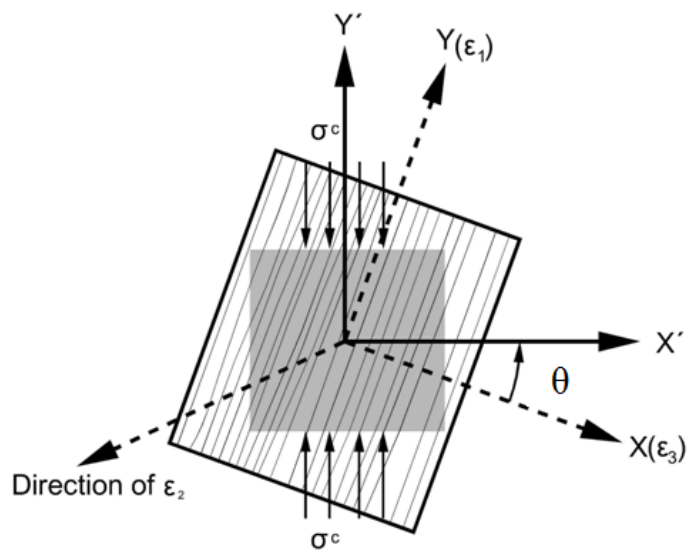

Figure 3: New sample (dark rectangle) built from the initial blocks.

\section{Experimental results}

Two previous problems have to be solved. The first problem involves the values of the two Young's elastic moduli for this material and its structural size. Before this research, twenty blocks $(20 \mathrm{~cm} \times 20 \mathrm{~cm} \times 20 \mathrm{~cm})$ were tested under compression stresses within the elastic zone, obtaining the average values $E y=$ $9442 \mathrm{MPa}$ and $E x=621 \mathrm{MPa}$. All the blocks were loaded in fibre and transversal -to-fibre directions. Some samples show a high dispersion, but the average values fall into the expected ranges. The strains were recorded by the same strain gages to those used after measuring the strains in the hole-drilling procedure and in the point where the hole is going to be made. Consequently, elastic moduli are not obtained according to the conventional test procedures. The results are only valid for the drilling point, so it is a localized measure and it should be taken into consideration for the whole block. The barrel effect in the samples was eliminated using a layer of standard lithium grease on the contact surfaces between the samples and the jaws of the compression machine. This layer drastically reduces the dispersion and the anomalous values of the recorded strains. Lithium grease has been used in all the tests shown here in order to avoid as many errors as possible. It has also to be confirmed that the dimensions of the drill assure the stress relaxation in its surroundings (where the strain gages are placed). Previous tests have shown that greater drill depth does not affect the strains recorded in the three strain gages. A $21-\mathrm{mm}$ drill depth was reached in three blocks. Neglected variations of $\varepsilon_{1}, \varepsilon_{2}$, and $\varepsilon_{3}$ in the three blocks were detected up to a depth of $16 \mathrm{~mm}$. 
Ten blocks have been loaded under axial compression in the fibre direction. The relaxed strains values after drilling a hole in Side 1 (fig. 4, left) are shown in table 1. These blocks have also been tested under compression stresses in the transversal/tangential direction (the $x$ axis) in the opposite side. The registered strains in Side 2 (opposite to Side 1) are shown in Table 2 (fig. 4, middle). The results for the samples cut with tilted-fibre direction with respect to the vertical direction are shown in Tables 3 and 4 (fig. 4, right). The hole-drilling test has been applied to both sides of the tilted-fibre blocks and therefore two values of $c_{22}$ per block have been obtained. The constants of compliance for each test and their average values obtained from results in the tables 1 to 4 and the eqns (5) to (12) are shown in table 5. Results for the block number 4 suggest stresses under tensile loads and they have been not considered in the next analysis. These anomalous results may be due to a deficient process of lubrication on the contact surfaces between the sample and the load group of the machine in laboratory. In table 5 , the results for this block have been eliminated.
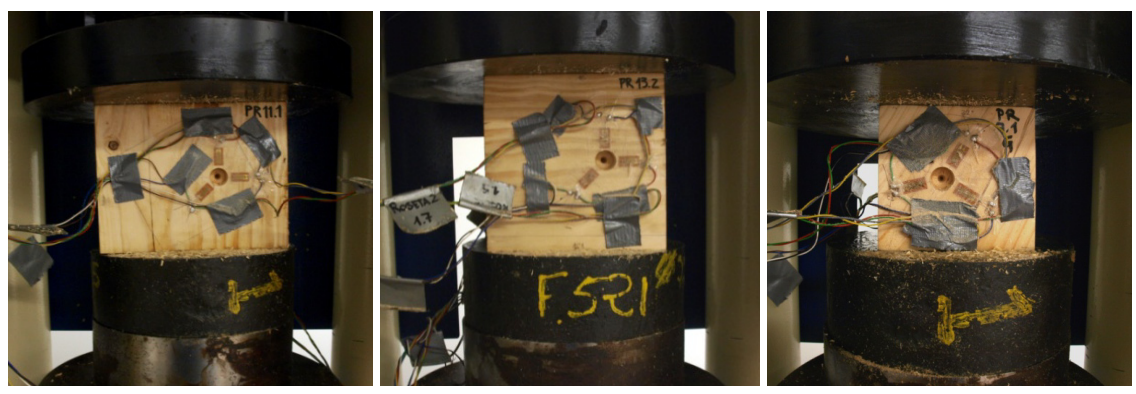

Figure 4: Samples tested in the fibre direction (left), perpendicular-to-fibre direction (middle) and tilted to the vertical load direction (right)

Table 1: Hole-drilling results under axial compression (fibre direction) on Side 1. "BFi" means Block tested in the Fibre direction for block number "i".

\begin{tabular}{|c|c|c|c|c|c|c|c|c|c|c|}
\hline & BF1 & BF2 & BF3 & BF4 & BF5 & BF6 & BF7 & BF8 & BF9 & BF10 \\
\hline $\begin{array}{c}\sigma y(\mathrm{MPa}) \\
\varepsilon_{1}\end{array}$ & -2.27 & -2.08 & -2.20 & -1.82 & -2.34 & -2.36 & -2.45 & -3.70 & -3.52 & -2.59 \\
\hline $\begin{array}{c}(\mu \mathrm{m} / \mathrm{m}) \\
\varepsilon_{2} \\
(\mu \mathrm{m} / \mathrm{m})\end{array}$ & 302 & 1779 & 101 & -68 & 601 & 1261 & 765 & 1181 & 770 & 731 \\
\hline $\begin{array}{c}\varepsilon_{3} \\
(\mu \mathrm{m} / \mathrm{m})\end{array}$ & 829 & 463 & -379 & 336 & 736 & 1243 & 471 & 10 & -100 & 413 \\
\hline
\end{tabular}


Table 2: Hole-drilling results under transversal compression on Side 2. "BTi" means Block tested in the Transversal direction for block number "i".

\begin{tabular}{|c|c|c|c|c|c|c|c|c|c|c|}
\hline & BT1 & BT2 & BT3 & BT4 & BT5 & BT6 & BT7 & BT8 & BT9 & BT10 \\
\hline $\begin{array}{c}\sigma x(\mathrm{MPa}) \\
\varepsilon_{1}\end{array}$ & -2.30 & -2.66 & -2.38 & -1.96 & -2.40 & -2.37 & -2.20 & -2.70 & -2.73 & -2.52 \\
\hline $\begin{array}{c}(\mu \mathrm{m} / \mathrm{m}) \\
\varepsilon_{2} \\
(\mu \mathrm{m} / \mathrm{m})\end{array}$ & -479 & -745 & -508 & -541 & -4 & 563 & 329 & 242 & 571 & 42 \\
\hline $\begin{array}{c}\varepsilon_{3} \\
(\mu \mathrm{m} / \mathrm{m})\end{array}$ & 2440 & 834 & 305 & 41 & 974 & 692 & 1685 & 1188 & 1701 & 1266 \\
\hline
\end{tabular}

Table 3: Hole-drilling results under vertical compression for blocks with the fibre direction tilted. "B1.i" means Block "i" tested on the Side 1.

\begin{tabular}{|c|c|c|c|c|c|c|c|c|c|c|}
\hline & B1.1 & B1.2 & B1.3 & B1.4 & B1.5 & B1.6 & B1.7 & B1.8 & B1.9 & B1.10 \\
\hline $\begin{array}{c}\sigma y^{\prime} \\
(\mathrm{Mpa})\end{array}$ & -4.17 & -4.95 & -4.13 & -4.21 & -4.05 & -3.96 & -4.22 & -4.5 & -4.22 & -4.29 \\
\hline $\begin{array}{c}\varepsilon_{1} \\
(\mu \mathrm{m} / \mathrm{m})\end{array}$ & 1443 & 353 & 525 & -407 & 786 & 277 & 266 & 440 & 41 & 244 \\
\hline $\begin{array}{c}\varepsilon_{2} \\
(\mu \mathrm{m} / \mathrm{m})\end{array}$ & -816 & -1217 & -1660 & 300 & -1337 & -231 & -160 & -1266 & 136 & -141 \\
\hline $\begin{array}{c}\varepsilon_{3} \\
(\mu \mathrm{m} / \mathrm{m})\end{array}$ & -304 & 819 & -1255 & 641 & 671 & 760 & 969 & 866 & 375 & 1288 \\
\hline
\end{tabular}

Table 4: Hole-drilling results under vertical compression for blocks with the fibre direction tilted. "B2.i" means Block number "i" tested on the Side 2.

\begin{tabular}{|c|c|c|c|c|c|c|c|c|c|c|}
\hline & B2.1 & B2.2 & B2.3 & B2.4 & B2.5 & B2.6 & B2.7 & B2.8 & B2.9 & B2.10 \\
\hline$\theta\left(^{\circ}\right)$ & -20.5 & -27 & -31 & -35 & -26 & -34 & -39.5 & -27 & -25 & -32.5 \\
\hline $\begin{array}{c}\sigma y^{\prime} \\
(\mathrm{Mpa})\end{array}$ & -4.17 & -4.03 & -4.32 & -4.21 & -4.05 & -3.98 & -4.26 & -4.31 & -4.76 & -4.34 \\
\hline $\begin{array}{c}\varepsilon_{1} \\
(\mu \mathrm{m} / \mathrm{m})\end{array}$ & 76 & 303 & -188 & -508 & 1024 & 972 & 364 & 341 & 555 & 396 \\
\hline $\begin{array}{c}\varepsilon_{2} \\
(\mu \mathrm{m} / \mathrm{m})\end{array}$ & -684 & -550 & -16 & -548 & -959 & -807 & 11 & 608 & 109 & -27 \\
\hline $\begin{array}{c}\varepsilon_{3} \\
(\mu \mathrm{m} / \mathrm{m})\end{array}$ & 446 & 1322 & 971 & 1149 & -596 & 535 & 515 & 350 & 1672 & 810 \\
\hline
\end{tabular}


Table 5: Constants of compliance for $E x=621 \mathrm{MPa}$ and $E y=9442 \mathrm{MPa}$. "Bi" means Block number “i”. Block 4 has been eliminated.

\begin{tabular}{|c|c|c|c|c|c|c|c|c|c|c|}
\hline & $\mathrm{B} 1$ & $\mathrm{~B} 2$ & $\mathrm{~B} 3$ & $\mathrm{~B} 5$ & $\mathrm{~B} 6$ & $\mathrm{~B} 7$ & $\mathrm{~B} 8$ & $\mathrm{~B} 9$ & $\mathrm{~B} 10$ & $\begin{array}{c}\text { Ave- } \\
\text { rage }\end{array}$ \\
\hline$c_{11}$ & -0.322 & -2.069 & -0.111 & -0.622 & -1.294 & -0.756 & -0.774 & -0.530 & -0.682 & -0.796 \\
\hline$c_{21}$ & -0.365 & -0.539 & 0.417 & -0.762 & -1.275 & -0.466 & -0.007 & 0.069 & -0.385 & -0.368 \\
\hline$c_{31}$ & -0.884 & -0.514 & 0.308 & -0.259 & 0.288 & 0.058 & -0.037 & -0.072 & -0.436 & -0.172 \\
\hline$c_{13}$ & 0.505 & 0.678 & 0.517 & 0.004 & -0.576 & -0.363 & -0.218 & -0.507 & -0.040 & 0 \\
\hline \multirow{2}{*}{$c_{23}$} & -0.781 & -0.759 & -0.311 & -0.982 & -0.708 & -1.857 & -1.070 & -1.509 & -1.216 & -1.021 \\
\hline \multirow{2}{*}{$c_{33}$} & -2.574 & -2.506 & -0.822 & -3.206 & -0.483 & -1.831 & -2.680 & -3.854 & -2.338 & -2.255 \\
\hline \multirow{2}{*}{$c_{22}$} & -2.991 & -2.747 & -1.694 & -3.995 & -3.115 & -2.267 & -2.265 & -0.284 & -1.553 & \multirow{2}{*}{-1.980} \\
\cline { 2 - 8 } & -2.480 & -2.261 & 0.487 & -3.422 & -3.427 & -2.083 & 0.285 & -0.411 & -1.412 & \\
\hline
\end{tabular}

Once the constants of compliance have been obtained (see average values of table 5), six new blocks are tested only in the transversal/tangential direction to check the validity of those values. The hole-drilling procedure was applied in one side after loading the samples at laboratory under uniaxial compression (the $x$ direction at right in fig. 2). The relaxed strains and the constants of compliance, table 6, have to reproduce the known load of machine. From eqn. (1), the stresses from the relaxed strains can be obtained using the following expression:

$$
\left(\begin{array}{c}
\sigma_{y} \\
\sigma_{x y} \\
\sigma_{x}
\end{array}\right)=\sqrt{E_{x} E_{y}}\left(\begin{array}{ccc}
c_{11} & 0 & c_{13} \\
c_{21} & c_{22} & c_{23} \\
c_{31} & 0 & c_{33}
\end{array}\right)^{-1}\left(\begin{array}{l}
\varepsilon_{1} \\
\varepsilon_{2} \\
\varepsilon_{3}
\end{array}\right)
$$

where $c i j$ are the average values of the constants of compliance shown in table 5. The results in table 6 compare the foreseen loads from eqn. (13) and the known machine loads.

Table 6: Summary of the results for the stresses obtained using the holedrilling method in comparison with the applied stresses at laboratory on six new checking blocks." NBi” means New Block number "i”".

\begin{tabular}{|l|c|c|c|c|c|c|}
\hline & NB1 & NB2 & NB3 & NB4 & NB5 & NB6 \\
\hline$\theta\left({ }^{\circ}\right)$ & -90 & -90 & -90 & -90 & -90 & -90 \\
\hline $\begin{array}{l}\text { Applied machine load (Mpa) } \\
\begin{array}{l}\text { Stresses obtained by Hole Drilling } \\
\text { method (Mpa) }\end{array}\end{array}$ & -4.64 & -4.37 & -4.35 & -4.31 & -4.29 & -4.40 \\
\hline $\begin{array}{l}\text { Differences between applied and } \\
\text { obtained stresses (Mpa) }\end{array}$ & -0.11 & -3.41 & -4.10 & -4.46 & -2.61 & -4.02 \\
\hline Error (\%) & 2 & 22 & 6 & 3 & 39 & 9 \\
\hline
\end{tabular}




\section{Discussion}

The final objective of the research is the deduction of the real stresses on timber structures in service and preferably in elements of existing buildings and civil structures, where not much technical information is available. Therefore, the material conditions are natural (as it was just taken from the forest without special treatments), and the dimensions of the elements are large. The tested material and the design of samples reproduce the most common timber structures conditions in many areas of Europe [15]. All the values of the parameters involved in this research have been specifically deduced from the laboratory tests, and no value has been taken from the bibliography. In these conditions, the results shown in table 6 are very acceptable because the hole-drilling procedure approaches the real and unknown stresses in five of six blocks less than $22 \%$ ( $83 \%$ of the samples), which means that the tests performed for constants of compliance determination are correct and good [3]; the confidence interval for the constants of compliance (table 5) to $80 \%$ are: $c_{11}=-0.796 \pm 0.2, c_{21}=-0.368 \pm$ $0.2, \quad c_{31}=-0.172 \pm 0.1, \quad c_{13}=0 \pm 0.1, \quad c_{23}=-1.021 \pm 0.1, \quad c_{33}=-2.255 \pm 0.4$ and $c_{22}=-1.980 \pm 0.3$. The values of the relaxed strain $\mathrm{s}$ recorded by the strain gages (tables 1 to 4) can be considered without error because these values were accepted when no variations of the strains were detected during a five minute period. The foreseen error by the standard unit does not exceed the $1 \%$ for each strain recorded.

Attention has to be given to the tilted-fibre direction (fig. 3), which yields the obtainment of $c_{22}$. The tests in transversal/tangential direction are focused on the final objective of the research and are easily reproducible because neither the samples imposed nor the procedures are complex. Nevertheless, some experimental conditions have to be taken into account; the adequate lubrication of the contact surfaces between the samples and the load group at laboratory, the availability of a well-tested strains recorded unit and the avoidance of defects (cracks and knots) in the analyzed areas. Only one block gave anomalous results in the process to obtain the constants of compliance, most likely due to the barrel effect or unexpected defects near the analyzed zone. The authors consider the results to be relevant to the development of a method to deduce the real stresses in beams of timber structures. The applicability of the results to other kind of wood can be immediate.

After this experimental campaign, the authors will perform flexion tests in beams of the same material. The procedure will be similar to that used here.

\section{Acknowledgements}

The authors acknowledge the scientific support of the professors Alfonso Basterra and Luis Acuña at the Valladolid University in Spain and the financial support of the Project PES 11/32 of the Basque Country University (UPV/EHU). 


\section{References}

[1] Kasal, B. \& Tannert, T. , In situ assessment of structural timber. RILEM state of the art reports, (7), 2010.

[2] ASTM, E. 837, Standard Test Method for Determining Residual Stresses by the Hole-Drilling Strain-Gage Method, 2013.

[3] Bo Kasal and Ronal W. Anthony. "Advances in in situ evaluation of timber structures". Prog. Struct. Engng. Mater., Vol. 6, pp. 94-103, 2004.

[4] Tannert, T., Anthony, R. W., Kasal, B., Kloiber, M., Piazza, M., Riggio, M. \& Yamaguchi, N., In situ assessment of structural timber using semidestructive techniques. Materials and structures, 47(5), pp. 767-785, 2014.

[5] Riggio, M., Anthony, R. W., Augelli, F., Kasal, B., Lechner, T., Muller, W., \& Tannert, T., In situ assessment of structural timber using nondestructive techniques. Materials and Structures, 47(5), pp.749-766, 2014.

[6] Mathar, J. Determination of initial stresses by measuring the deformation around drilled holes. Trans. ASME, 56(4), pp. 249-254, 1934.

[7] Schajer, G. S., Hole-drilling residual stress measurements at 75: origins, advances, opportunities. Experimental mechanics, 50(2), pp. 245-253, 2010.

[8] Mainjot, A. K., Schajer, G. S., Vanheusden, A. J., \& Sadoun, M. J., Residual stress measurement in veneering ceramic by hole-drilling. Dental materials, 27(5), pp. 439-444, 2011.

[9] Sanchez-Beitia, S., \& Schueremans, L., The hole drilling technique for on site deduction of the stresses states in stone masonry by using eight strain gages. J. Constr. Build. Mater., Vol. 23(5), pp. 2041-2046, 2009.

[10] Sanchez-Beitia, S., Schueremans, L. \& Van Balen, K., In site stress measurement on the piers of the Saint Jacobs church in Leuven (Belgium). Int. J. Archit. Heritage: Conserv. Anal. Restor., Vol. 3(2), pp. 110-125, 2009.

[11] Sanchez-Beitia, S. \& Roca P., Hole Drilling Technique for In-Site Stress Measurements of Masonry Piers: Analysis of the Santa Maria del Mar Cathedral in Barcelona, Spain. J. Architectural Eng. (ASCE), Vol. 20(3), pp. 05014002-1-5, 2014.

[12] Schajer, G.S. \& Yang, L., Residual-stress Measurement in Orthotropic Materials Using the Holedrilling Method. Experimental Mechanics, Vol. 34(4), pp. 324-33, 1994.

[13] Bert, C.W. \& Thompson, G.L., A Method for Measuring Planar Residual Stresses in Rectangularly Orthotropic Materials. J. Composite Mat., Vol. 2 (2), pp. 244-253, 1968.

[14] Standard UNE-EN 56544:2011 Clasificacion visual de la madera aserrada para uso estructural. Madera de coniferas (in Spanish), 2011.

[15] Basterra, LA. et al., "Strength testing of Poplar duo beams, Populus x euramericana (Dode) Guiniercv. I-214, with fibre reinforcement". $J$. Constr. Build. Mater., Vol. 36, pp. 90-96, 2012. 